\title{
Immunodiagnosis of Canine Visceral Leishmaniasis Using Mimotope Peptides Selected from Phage Displayed Combinatorial Libraries
}

\author{
Christina Monerat Toledo-Machado, ${ }^{1}$ Ricardo Andrez Machado de Avila, ${ }^{2}$ \\ Christophe NGuyen, ${ }^{3}$ Claude Granier, ${ }^{3}$ Lilian Lacerda Bueno, ${ }^{1}$ \\ Claudia Martins Carneiro, ${ }^{4}$ Daniel Menezes-Souza, ${ }^{1}$ Rubens Antonio Carneiro, ${ }^{5}$ \\ Carlos Chávez-Olórtegui, ${ }^{2}$ and Ricardo Toshio Fujiwara ${ }^{1}$
}

\author{
${ }^{1}$ Departamento de Parasitologia, ICB, Universidade Federal de Minas Gerais, CP 486, Belo Horizonte 31270-901, MG, Brazil \\ ${ }^{2}$ Departamento Bioquímica e Imunologia, ICB, Universidade Federal de Minas Gerais, CP 486, Belo Horizonte 31270-901, MG, Brazil \\ ${ }^{3}$ SysDiag CNRS-BioRad UMR 3145, Cap Delta/Parc Euromédecine, 1682 rue de la Valsière, CS 61003, \\ 34184 Montpellier Cedex 4, France \\ ${ }^{4}$ Departamento de Análises Clínicas, Escola de Farmácia, Universidade Federal de Ouro Preto, Ouro Preto 35400-000, MG, Brazil \\ ${ }^{5}$ Escola de Veterinária, Universidade Federal de Minas Gerais, CP 486, Belo Horizonte 31270-901, MG, Brazil
}

Correspondence should be addressed to Ricardo Toshio Fujiwara; fujiwara@icb.ufmg.br

Received 17 November 2014; Revised 27 December 2014; Accepted 11 January 2015

Academic Editor: Mehdi Chenik

Copyright (C) 2015 Christina Monerat Toledo-Machado et al. This is an open access article distributed under the Creative Commons Attribution License, which permits unrestricted use, distribution, and reproduction in any medium, provided the original work is properly cited.

\begin{abstract}
ELISA and RIFI are currently used for serodiagnosis of canine visceral leishmaniasis (CVL). The accuracy of these tests is controversial in endemic areas where canine infections by Trypanosoma cruzi may occur. We evaluated the usefulness of synthetic peptides that were selected through phage display technique in the serodiagnosis of CVL. Peptides were chosen based on their ability to bind to IgGs purified from infected dogs pooled sera. We selected three phage clones that reacted only with those IgGs. Peptides were synthesized, polymerized with glutaraldehyde, and used as antigens in ELISA assays. Each individual peptide or a mix of them was reactive with infected dogs serum. The assay was highly sensitive and specific when compared to soluble Leishmania antigen that showed cross-reactivity with anti-T. cruzi IgGs. Our results demonstrate that phage display technique is useful for selection of peptides that may represent valuable synthetic antigens for an improved serodiagnosis of CVL.
\end{abstract}

\section{Introduction}

Canine visceral leishmaniasis (CVL) caused by Leishmania (Leishmania) infantum chagasi is a widespread zoonotic disease of both the Old and the New World [1] leading to a considerable number of deaths. Domestic dogs are considered the main animal reservoir hosts of the disease $[2,3]$. Most infected dogs do not present clinical signs but are seropositive particularly in endemic areas of CVL in the World [2, 4-7]. The seroprevalence of CVL in areas of endemicity in the Mediterranean Basin and the Middle East, including Iran, has been reported to be $10-37 \%[6,8]$.
Euthanasia of seropositive dogs has been adopted as a mainstay control measure in some countries [9].

The Brazilian Ministry of Health recommends the use of an immunoenzymatic assay (ELISA) and an indirect immunofluorescence antibody test (IFAT) for the diagnosis of canine visceral leishmaniasis (CVL), employed as criteria for the culling of seropositive dogs in surveillance and control programs for visceral leishmaniasis (VL) [10]. Both the accuracy of these tests and the process of dog culling promote a controversial impact of the leishmaniasis infection [11, 12]. However, the development of an effective diagnosis test can be critical for the control and the possible eradication of VL; 
more sensitive and specific tests may be especially helpful to achieve this goal [13].

Over the past years, synthetic peptides have been used successfully as antigens for the in vitro diagnosis of many parasitic diseases [14]. Phage display of random peptides has become an alternative method for the study of molecular interactions in many areas of protein science, including antigen-antibody interactions. It has been shown that linear epitopes, as well as mimotopes that mimic discontinuous epitopes of an antigen, can be identified by the screening of phage libraries with monoclonal or polyclonal antibodies [15, 16]. Phage display in neglected disease research has proven successful not only in mapping the protein-protein interactions that are important in the etiologic agent biology, but also in the identification of molecules that might be exploited in the design of therapeutic agents, vaccines, or immunodiagnostics [17-19].

In order to search for diagnostic epitopes without previous knowledge of protein structure, we tested phage-borne libraries displaying foreign peptides at the surface of the major pVIII coat proteins for their capacity to bind anti- $L$. infantum chagasi proteinantigen (LiPA) IgGs purified from the sera of dogs with visceral leishmaniasis. Phage clones reactive with anti-LiPA IgGs were also tested for reactivity with IgGs purified from the sera of dogs experimentally infected with T. cruzi, because of the known cross reaction between visceral leishmaniasis antibodies and Chagas' disease antibodies in dogs [20]. In order to estimate the diagnostic accuracy, we found three peptides that could successfully be used as antigens in ELISA assays for a specific immunodiagnosis of canine visceral leishmaniasis without cross reaction with circulating antibodies of T. cruzi experimentally infected dogs.

\section{Material and Methods}

2.1. Study Dogs. For biopanning assay thirty-eight sera from L. infantum chagasi naturally infected dogs of both genders were used. For the ELISA assays, thirty-eight sera were obtained from beagle dogs experimentally infected with $L$. infantum chagasi for leishmaniasis studies. The infection was certified through parasitological tests that were conducted on bone marrow cells examined by optical microscopy and immunological tests (ELISA and RIFI). Additionally, for both assays, thirty-eight sera from uninfected dogs were used as negative controls. In order to evaluate cross-reactivity on ELISA assays we also used fifteen sera from dogs experimentally infected with $T$. cruzi parasite obtained from the serum bank of the Laboratório de Imunologia e Genômica de Parasitos (UFMG).

Proof of dog infection was attested by a positive immunofluorescence titre (IFAT) at the threshold titer of 1: 40 serum dilution, a positive reactivity in ELISA, and a parasitological diagnosis of Leishmania. Antibodies from sera of 38 healthy dogs displaying negative IFAT and parasitological tests were included as uninfected controls. Briefly, the clinical evaluation assessed typical clinical signs for symptomatic visceral leishmaniasis, including lymphadenopathy, decrease of weight and opaque eye, alopecia, eczema, and skin ulcers.
In order to verify possible infection with different pathogens (Babesia canis, Ehrlichia canis, and Trypanosoma cruzi) in all L. infantum chagasi naturally infected animals, parasitological exams were performed in a private laboratory in Belo Horizonte, Minas Gerais, Brazil.

All dogs were maintained in a kennel of Institute of Biological Sciences in the Universidade Federal de Minas Gerais, Belo Horizonte, Brazil, according to university's ethic committee for clinical research (CETEA) protocol 122/2009.

2.2. Production of L. infantum chagasi Protein Antigen (LiPA). L. infantum chagasi (MHOM/BR/1975/BH46) was grown at $24^{\circ} \mathrm{C}$ in Schneider's medium (Sigma, St. Louis, MO, USA) supplemented with $20 \%$ heat-inactivated fetal bovine serum (FBS; Sigma), $200 \mathrm{U} / \mathrm{mL}$ penicillin, and $100 \mu \mathrm{g} / \mathrm{mL}$ streptomycin, $\mathrm{pH}$ 7.2. Protein antigens of L. infantum chagasi (LiPA) were prepared from stationary phase promastigotes, submitted to 7 cycles of freezing (liquid nitrogen) and thawing $\left(42^{\circ} \mathrm{C}\right)$, followed by ultrasonication (Ultrasonic processor, GEX600) with cycles of $10 \mathrm{sec}$ for $2 \mathrm{~min}$ at $35 \mathrm{MHz}$. The extracts were then submitted to centrifugation at $8,000 \times \mathrm{g}$ for $20 \mathrm{~min}$ at $4^{\circ} \mathrm{C}$. The supernatant was collected and stored at $-70^{\circ} \mathrm{C}$. The protein concentration was estimated by the Bradford method [21].

2.3. Preparation of Antibodies for Biopanning. Antibodies used for biopanning (i.e., immunocapture of phages binding to target antibodies) were initially purified from 38 sera from L. infantum chagasi naturally infected dogs of both genders. Fifteen serum samples of dogs experimentally infected with Trypanosoma cruzi parasite were also collected.

Polyclonal IgGs to LiPA (anti-LiPA IgGs) used for biopanning were purified from a pool of dogs with VL, using ammonium sulfate precipitation and filtration through Protein A-Sepharose 4B column [22]. Following elution and neutralization using $\mathrm{NaOH} 0.1 \mathrm{M}$, the IgG fraction was dialyzed against PBS $1 \mathrm{x}$ and the protein concentration was determined by the Bradford method [21]. IgGs from uninfected controls (normal IgG) were also fractionated as described before. IgGs from T. cruzi infected dogs were obtained. The reactivity against LiPA of anti-LiPA IgGs and normal IgGs was confirmed by indirect ELISA.

2.4. Ethics Statement. All sera samples were obtained from the Veterinary Hospital of the Federal University of Minas Gerais (UFMG) and the experiments were performed in compliance with the university's ethic committee for clinical research (CETEA), protocol 122/2009. All sera were stored at $-20^{\circ} \mathrm{C}$ until use. All dog owners gave permission to have their animals sampled.

2.5. Biopanning. The M13 phage libraries expressing $15-$ mer $\left(X_{15}\right)$ and 12-mer peptides including two fixed cysteine residues $\left(X_{C} X_{8} \mathrm{CX}\right)$ were previously described by [23] and obtained from Dr. John Scott (Simon Fraser University, Burnaby, British Columbia, Canada). Three cycles of biopanning were performed as described by Ferrières et al. (2000) [24]. Anti-LiPA IgGs were coated onto a polystyrene Petri dish (10 $\times 1.5 \mathrm{~cm}$, Falcon 1029) overnight at $4^{\circ} \mathrm{C}$ at a concentration of 
$5 \mu \mathrm{g} / \mathrm{mL}$ for the first two rounds of panning and a concentration of $0.5 \mu \mathrm{g} / \mathrm{mL}$ for the last panning in $100 \mathrm{mM} \mathrm{NaHCO}_{3}$, $\mathrm{pH} 8.6$, on a shaking platform. For the first panning, $5 \times$ $10^{12}$ transducing units (TU) of each library were incubated with the absorbed IgG. After incubation, unbound phages were washed with TBS (Tris $50 \mathrm{mM}, \mathrm{NaCl} 150 \mathrm{mM}, \mathrm{pH} 7.5$ ) containing $0.05 \%(\mathrm{v} / \mathrm{v})$ Tween 20 , and bound phages were removed by elution with $0.1 \mathrm{M}$ glycine, $\mathrm{pH} 2.2$, containing $0.1 \%$ BSA. Eluted phages were then used to infect Escherichia coli K91 cells. After three rounds of enrichment, individual phage clones were isolated and further analyzed [24].

2.6. ELISA Analysis after Three Rounds of Panning. ELISA plates (Falcon 3912, Becton Dickinson, Oxnard, CA 93030) were coated with $1 \mu \mathrm{g} /$ well of anti-LiPA IgGs in $100 \mathrm{mM}$ $\mathrm{NaHCO}_{3}, \mathrm{pH} 8.6$, and overnight at $4^{\circ} \mathrm{C}$. Plates were washed with PBS $0.1 \%$ Tween $20(\mathrm{v} / \mathrm{v})$ and then blocked with PBS, $0.1 \%$ Tween 20 and $2 \%$ nonfat dried milk (w/v) for $1 \mathrm{~h}$ at $37^{\circ} \mathrm{C} .10^{10} \mathrm{TU}$ of phages, eluted after each round of panning, were then added to the plate and incubated for $2 \mathrm{~h}$ at $37^{\circ} \mathrm{C}$. Binding was detected using a peroxidase conjugated anti-M13 antibody (Roche Molecular Biochemicals) diluted 1:3000 in blocking buffer. After $1 \mathrm{~h}$ at $37^{\circ} \mathrm{C}$ and washing, the peroxidase substrate was added. The resulting color was measured at $492 \mathrm{~nm}$ with an automated microtiter plate reader (Model 450, Bio-Rad).

2.7. Screening. ELISA plates (Falcon 3912, Becton Dickinson, Oxnard, CA 93030) were coated with $1 \mu \mathrm{g} /$ well of anti-LiPA IgGs or anti- T. cruzi IgGs in $100 \mathrm{mM} \mathrm{NaHCO}_{3}, \mathrm{pH} 8.6$, and overnight at $4^{\circ} \mathrm{C}$. Plates were washed with PBS, $0.1 \%$ Tween $20(\mathrm{v} / \mathrm{v})$, and then blocked with PBS, $0.1 \%$ Tween 20, and 2\% nonfat dried milk (w/v) for $1 \mathrm{~h}$ at $37^{\circ} \mathrm{C} .10^{10} \mathrm{TU}$ of individual phages was isolated after third panning and $50 \mu \mathrm{L}$ of blocking buffer was then added to each well. Phage particles were incubated for $2 \mathrm{~h}$ at $37^{\circ} \mathrm{C}$. Binding was detected using a peroxidase conjugated anti-M13 antibody (Roche Molecular Biochemicals) diluted 1:3000 in blocking buffer. After $1 \mathrm{~h}$ at $37^{\circ} \mathrm{C}$ and washing, the peroxidase substrate was added. The resulting color was measured at $492 \mathrm{~nm}$ with an automated microtiter plate reader (Model 450, Bio-Rad). Afterwards, the twelve clones were checked by ELISA for their ability to bind to anti T. cruzi dog IgGs.

2.8. DNA Sequencing, Synthesis, Chromatography, and Mass Spectrometry of Soluble Peptides. Approximately, $9 \mu \mathrm{g}$ of single-stranded DNA was purified using the QIA prep Spin M13 protocol (Qiagen). Sequencing reactions were carried out according to the dideoxy chain termination method [25], using the ABI Prism Kit (PE Applied Biosystems) for the automatic method with ABI PRISM 377 (PerkinElmer). The primer reverse $5^{\prime}$-TCGGCAAGCTCTTTTAGG-3' was used for sequencing. The sequences obtained were translated.

The peptides TTDDDKLKKTLTYRS, KCPSIPGAVLCV, and ICARQDPAGNCS were synthesized in ResPep SL Synthesizer by Fmoc chemistry [26]. After synthesis, the peptides were deprotected and released from the resin by trifluoroacetic acid (TFA) treatment in the presence of the appropriate scavengers. The peptides were lyophilized and their purity was assessed by HPLC and their mass was confirmed by mass spectrometry according to de Avila et al. (2011) [27].

2.9. Glutaraldehyde Link Reaction. Individual peptides and the combination of three peptides (pool) were polymerized using glutaraldehyde as cross-linking reagent [28]. Briefly, $10 \mu$ moles of each peptide was diluted in $1 \mathrm{~mL}$ of PBS and an equal volume of $1 \%$ GLUT $(20 \mathrm{mM})$ in PBS was then slowly added to the solution over the course of 1 hour under constant stirring at $4^{\circ} \mathrm{C}$. The reaction was allowed to proceed for an additional hour and the free aldehyde coupling groups and the Schiff's base intermediates were reduced by the addition of $\mathrm{NaBH}_{4}(10 \mathrm{mg} / \mathrm{mL})$. At the end of the reaction, the solution containing polymerized peptides was dialyzed overnight against PBS.

2.10. Diagnostic ELISA for Canine Sera. ELISA was carried out to detect circulating antibodies that recognized polymerized peptide in canine sera. ELISA assays microtiter plates were coated with $50 \mu \mathrm{L} /$ well of each polymerized peptide or with the polymerized mixture of the three peptides or with $L$. infantum chagasi total protein antigen $(2.5 \mathrm{mg} / \mathrm{mL})$ in Milli-Q water. The wells were blocked with $200 \mu \mathrm{L} /$ well of $5 \% \mathrm{BSA}$ in $\mathrm{PBS}$ at $37^{\circ} \mathrm{C}$ for $1 \mathrm{~h}$. After the wells had been washed twice with PBS containing 0.05\% Tween 20 (PBST), $100 \mu \mathrm{L} /$ well of $L$. infantum chagasi infected dog serum; healthy dog serum; and Ehrlichia canis, Babesia canis, and T. cruzi infected dog serum diluted 1:100 in PBS- BSA $2.5 \%$ was added and incubated at $37^{\circ} \mathrm{C}$ for $1 \mathrm{~h}$. The wells were washed six times with PBS-T, incubated with $100 \mu \mathrm{L} /$ well of anti-dog IgG conjugated with peroxidase (Sigma), diluted $1: 2000$ in PBS-BSA $2.5 \%$ at $37^{\circ} \mathrm{C}$ for $1 \mathrm{~h}$ and washed six times with PBST. After incubation with $100 \mu \mathrm{L} /$ well of ophenylenediamine solution $(0.33 \mathrm{mg} / \mathrm{mL}$ in citrate buffer, $\mathrm{pH} 5.2$, in the presence of $0.04 \%$ hydrogen peroxide) for $15 \mathrm{~min}$ at room temperature, the optical density at $492 \mathrm{~nm}$ of each well was determined. The cut-off was determined according to ROC curve. The results of the ELISA peptides as antigens in dogs were compared with the immunoassay EIE-LVC kit (FIOCRUZ-Bio-Manguinhos, Brazil), which is the test currently recommended by the Brazilian Ministry of Health for screening seroreactive animals [29]. The assays were conducted according to the manufacturer's instructions.

2.11. Statistical Analysis. The lower limit of positivity (cutoff) was established for optimal sensitivity and specificity using the ROC (receiver operator curve) curve for all peptides used in this study and L. infantum chagasi antigen. The criterion to determine the cut-off value using the ROC curve was to select the point that showed higher sensitivity and specificity simultaneously. EIE-LVC ${ }^{\#}$ cut-off was obtained according to the manufacturer (twice the average of the negative control provided by the kit). Sensitivity (Se), specificity (Sp), predictive positive value (PPV), and predictive negative value $(\mathrm{PNV})$ were determined. The performance of each test was evaluated according to the area under curve (AUC) referent to the ROC curve and accuracy (AC). 


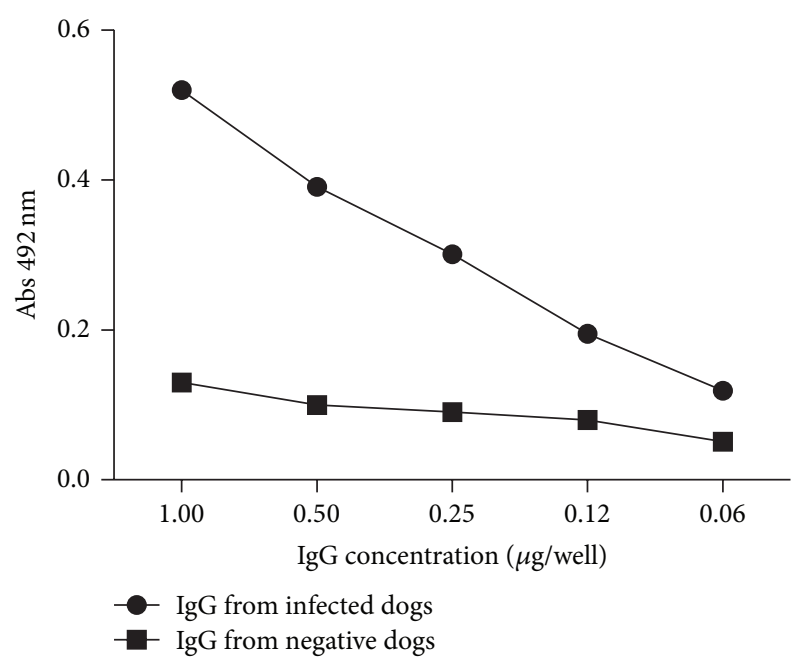

FIGURE 1: Reactivity of purified IgG antibodies against L. infantum chagasi antigen (LiPA). $10 \mu \mathrm{g}$ of affinity-purified IgGs from CVL dogs $(\bullet)$ and negative dogs ( $)$ was added to each well (from $10 \mu \mathrm{g}$ to $0.625 \mu \mathrm{g} /$ well) of microtiter plates coated with $50 \mu \mathrm{g} / \mathrm{mL} \mathrm{LiPA}$. The reaction was detected using a peroxidase conjugated anti-dog IgG antibody $(1: 2000)$. Absorbance values at $492 \mathrm{~nm}$ were means of duplicates.

The degree of agreement between ELISA assays using peptides, L. infantum chagasi antigen, and EIE-LVC BioManguinhos kit test was determined by the Kappa index $(\kappa)$ values with 95\% confidence intervals and interpreted according to the following Fleiss scale: $0.00-0.20$, poor; 0.21-0.40, fair; $0.41-0.60$, moderate; $0.61-0.80$, good; $0.81-0.99$, very good; and 1.00, perfect [30]. All of the statistical analyses were performed using GraphPad Prism (version 5.0) and GraphPad QuickCals (http://www.graphpad.com/quickcalcs/).

\section{Results}

3.1. Selection of Phages Recognized by Anti-LiPA IgGs and Mimotope Peptides Synthesis. For the screening of phageborne peptides from libraries, IgGs purified from sera of thirty-eight naturally infected and sixteen uninfected dogs were used. Levels of anti-LiPA antibodies were previously examined in sera samples collected one week before phage display experiments (data not shown). After fractionation of the pool of sera of infected or noninfected animal through Protein A-Sepharose 4B column, a dose-dependent reactivity of the purified IgGs towards LiPA was observed in an ELISA format (Figure 1).

In order to identify peptides that bind to anti-LiPA antibodies, four different phage libraries were screened. A significant enrichment of phage binding to the target antibodies was obtained after three rounds of panning (Figure 2(a)). One hundred and ninety-eight phage clones were randomly picked from the third round of selection, and twelve clones were selected based on their reactivity (absorbance at $492 \mathrm{~nm}$ $\geq 1.0$ ) against IgGs from L. infantum chagasi infected dogs (data not shown). Afterwards, the twelve clones were checked by ELISA for their ability to bind to anti-T. cruzi dog
IgGs. Clones 5, 6, and 11 were further selected due their high reactivity against Leishmania-specific IgGs and without cross-reactivity with IgGs from dogs with Chagas disease (Figure 2(b)).

The DNA sequences of clones 5, 6, and 11 were translated and the amino acid sequences of the peptides were deduced (Figure 2(c)). One peptide (peptide 11) was selected from the $X_{15}$ library expressing 15-mer linear peptides, whereas the other two peptides were selected from the $\mathrm{XCX}_{8} \mathrm{CX}$ library of constrained 12-mer peptides. The corresponding synthetic peptides, TTDDDKLKKTLTYRS, KCPSIPGAVLCV, and ICARQDPAGNCS, were chemically synthesized and purified by reverse phase chromatography and their correct molecular weights were confirmed by mass spectrometry (data not shown).

3.2. Sensitivity and Specificity of ELISA Tests with Synthetic Peptides for Serodiagnosis of CVL. In order to evaluate the antigen-specific dog antibody response against synthetic peptides, an ELISA was optimized to obtain the best signalto-noise ratio and to develop a reproducible and robust assay capable of capturing antibodies over a biologically relevant assay range. The EIE-LVC kit was used as a reference. ELISA cut-off values for peptides 5,6 , and 11 and pooled peptides (peptides 5+6+11) as antigens were 0.488, 0.698, 0.594, and 0.410 , respectively. In similar conditions, the cut-off values were 0.546 and 0.104 , for L. infantum chagasi antigen and EIE-LVC kit, respectively. The peptides were initially tested on sera of 38 dogs with L. infantum chagasi (CVL) (Figure 3, Table 1). Antibodies against peptides 5, 6, and 11 and pooled peptides were detected in $100 \%$ of the serum samples from these dogs. In order to evaluate specificity (Sp), serum samples from negative control dogs and samples from dogs infected by E. canis, B. canis, and T. cruzi were tested. Peptides 5 and 11 demonstrated an excellent specificity value (100.00\%) slightly better than the $97.10 \%$ obtained for peptide 6 and pooled peptides, which showed 2 false positive results in the T. cruzi group (Figure 3 and Table 1). Comparative analysis using either the crude antigen or the reference EIELVC ELISA demonstrated also high sensitivity (100.00\% and $94.74 \%$, resp.). However, these tests showed a poorer specificity $(76.81 \%$ and $68.12 \%$, resp.) due to the large number of false negative results in negative and T. cruzi group.

3.3. Measures of ELISA Performance and Analysis of Agreement between the Different Antigens Used in the Diagnosis of CVL. Measures of performance for the different tests evaluated are shown in Table 1. Maximum positive predictive value (PPV) was achieved by peptides 5 and 11 (100.00\%) followed by peptide 6 and pool (95.00\% for both). Excellent negative predictive values (NPV) were observed for all three peptides and their mix (100.00\%).

The area under the curve (AUC) and accuracy (AC) were used to compare the efficiency of different diagnostic tests [31]. Peptides 5 and 11 presented the highest AUC value $(1.0000)$ and accuracy $(\mathrm{AC}=1.0000)$, followed by peptide 6 $(\mathrm{AUC}=0.9980$ and $\mathrm{AC}=0.9780)$ and pool $(\mathrm{AUC}=0.9958$ and $\mathrm{AC}=0.9780)$ (Figure 4 and Table 1 ). The L. infantum 


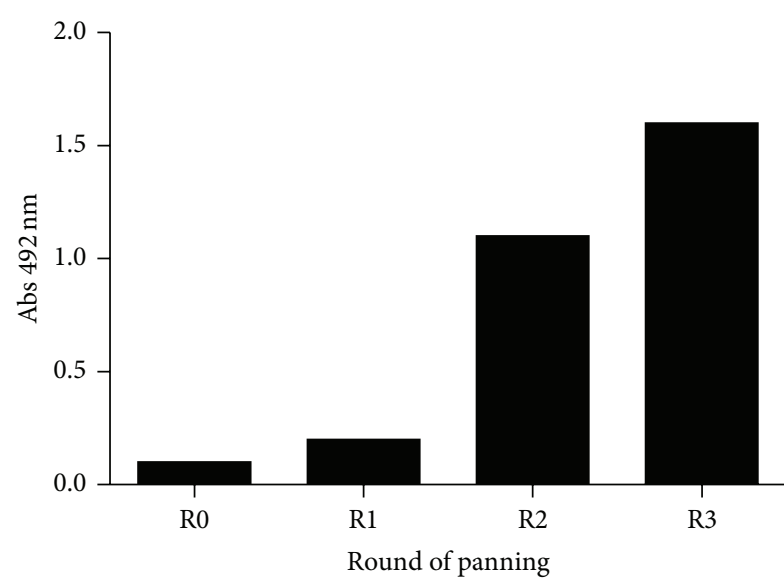

(a)

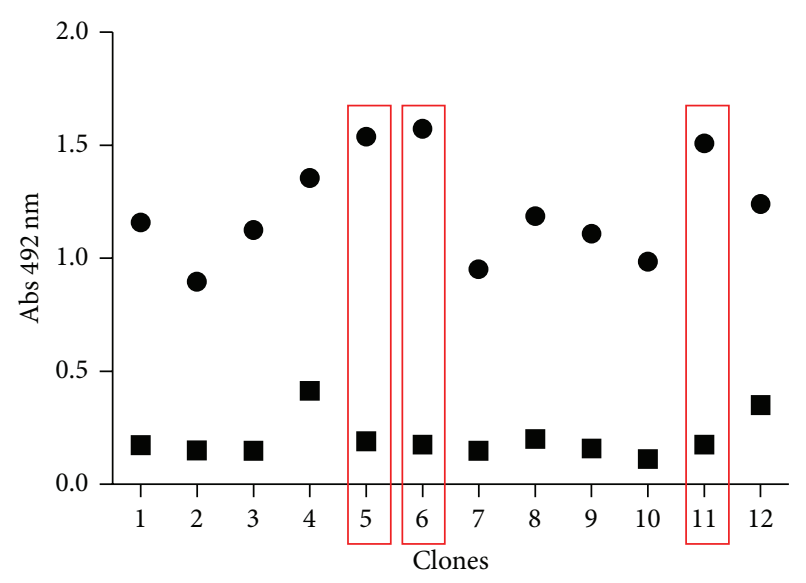

IgG anti-L. infantum

IgG anti-T. cruzi

(b)

Peptide 5-ICARQDPAGNCS

Peptide 6-KCPSIPGAVLCV

Peptide 11-TTDDDKLKKTLTYRS

(c)

Figure 2: (a) Enrichment of phage binding after three rounds of panning. $50 \mu \mathrm{L}$ of a $10^{10}$ transduction unit phage suspension collected after each round of panning was added to wells of microtiter plates coated with $5 \mu \mathrm{g} / \mathrm{mL}$ anti-LiPA IgG. Phages were detected using a peroxidase conjugated anti-M13 antibody (1:3000). Values of absorbance at $492 \mathrm{~nm}$ are means of duplicates. (b) Reactivity of individual clones isolated after panning 3. $50 \mu \mathrm{L}$ of a $10^{10}$ transduction unit phage suspension isolated after the third round of panning was added to each well of microtiter plates coated with $1 \mu \mathrm{g} /$ well of anti-L. infantum chagasi $\operatorname{IgGs}(\bullet)$ and anti-T. cruzi IgGs ( $\mathbf{(})$. Phages were detected using a peroxidase conjugated anti-M13 antibody (1:3000). Values of absorbance at $492 \mathrm{~nm}$ are means of duplicates. (c) The aminoacid sequences of the three selected peptides.

TABLE 1: Diagnostic performance of synthetic peptides, L. infantum chagasi antigen, and EIE-LVC Kit in sera of dogs.

\begin{tabular}{lcccccccc}
\hline Diagnostic test & FN & FP & Se $\%$ & Sp $\%$ & PPV \% & NPV \% & AUC & AC \\
\hline $5^{*}$ & $0 / 38$ & $0 / 69$ & 100.00 & 100.00 & 100.00 & 100.00 & 1.0000 & 1.0000 \\
$6^{*}$ & $0 / 38$ & $2 / 69$ & 100.00 & 97.10 & 95.00 & 100.00 & 0.9985 & 0.9813 \\
$11^{*}$ & $0 / 38$ & $0 / 69$ & 100.00 & 100.00 & 100.00 & 100.00 & 1.0000 & 1.0000 \\
Pep-Mix $^{*}$ & $0 / 38$ & $2 / 69$ & 100.00 & 97.10 & 95.00 & 100.00 & 0.9968 & 0.9813 \\
Ag $^{*}$ & $0 / 38$ & $16 / 69$ & 100.00 & 76.81 & 70.37 & 100.00 & 0.9851 & 0.8505 \\
EIE-LVC & $2 / 38$ & $22 / 69$ & 94.74 & 68.12 & 62.07 & 95.92 & NA & 0.7757 \\
\hline
\end{tabular}

Samples from healthy dogs and dogs with canine visceral leishmaniasis, T. cruzi, E. canis, or B. canis.

${ }^{*}$ Cut-off obtained by ROC curve.

${ }^{\#}$ Cut-off obtained according to the manufacturer.

NA: not applicable; FN: false negative; FP: false positive; Se: sensitivity; Sp: specificity; AUC: area under curve; PPV: positive predictive value; NPV: negative predictive value; AC: accuracy.

chagasi antigen and EIE-LVC kit showed a lower accuracy value (0.8352 and 0.8791 , resp.). The agreement between the serological tests using the Kappa Index is shown in Table 2. All peptides showed moderate agreement with EIE-LVC* and good agreement with crude leishmanial antigen.

\section{Discussion}

Accurate diagnosis of canine leishmaniasis is essential towards a more efficient control of this zoonosis in endemic areas where it occurs. Conventional parasitological techniques are highly specific but still represent time-consuming and invasive methods that are not appropriate for epidemiological surveillance or the daily routine of protocols for control of CVL. On the other hand, the use of rapid and reliable methods such serological assays for diagnosis of visceral leishmaniasis in dogs has been largely hampered by cross-reactivity with other canine pathogens [20,32], especially when crude antigens are employed [33].

The use of synthetic peptides [34] as final targets in serological assays would circumvent the reliance on parasite 

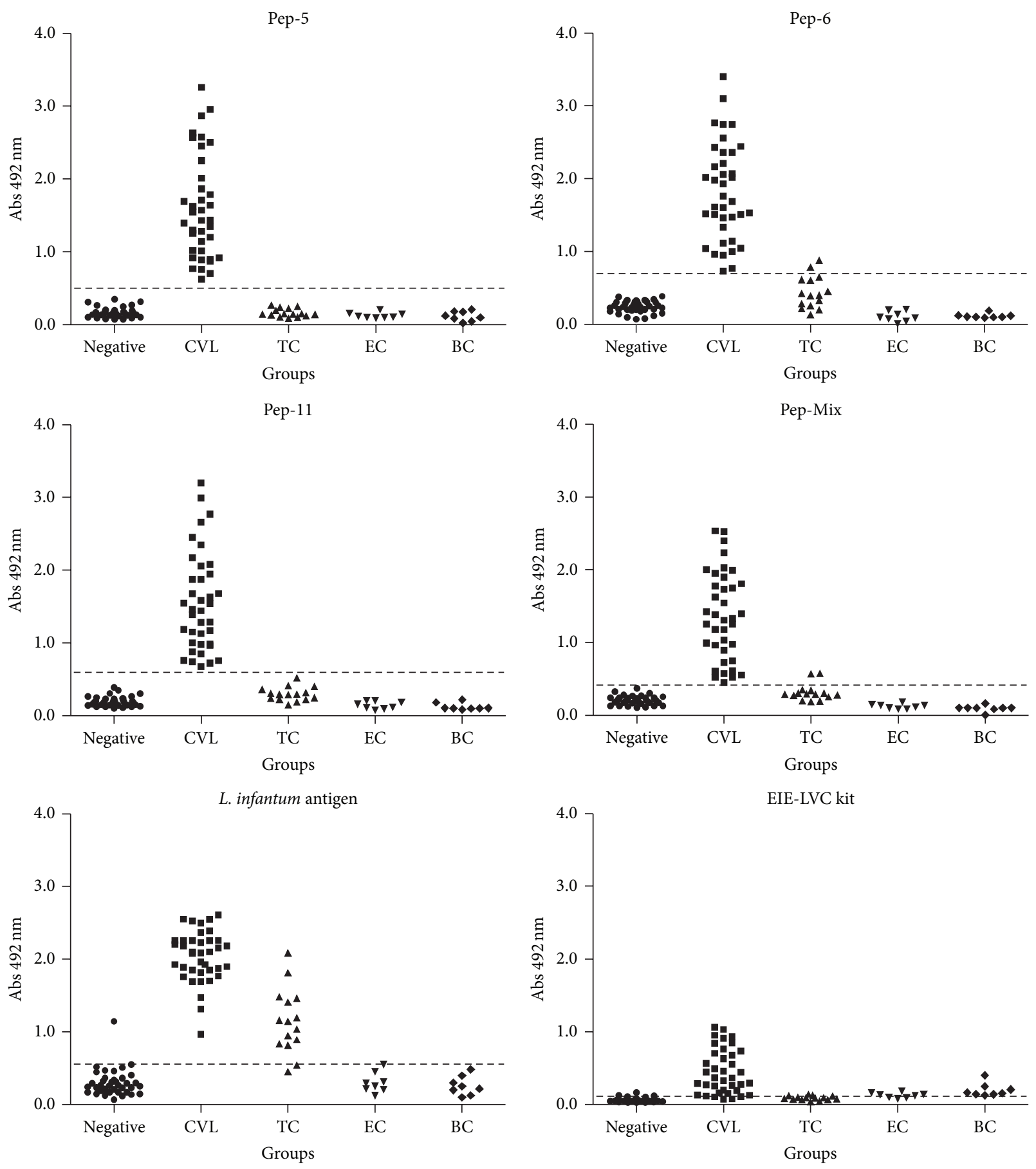

FIgURE 3: Comparison of ELISA reactivity of canine sera against individual phage-display selected peptides, the pool of peptides, the $L$. infantum chagasi antigen (LiPA), and reactivity in the EIE-LVC kit. ELISA was performed in different groups of dogs (negative/control group, CVL group, and TC/T. cruzi group). Cut-off was determined according to ROC curves.

extracts, which often do not provide reproducible results due to the variable nature of the protein content, thus contributing to the required standardization of the assay. Moreover, the chemical synthesis of the peptides is relatively simple and does not require the manipulation of pathogenic organisms. In the current study, we assessed the potential of phage display technology [15] to select specific peptide sequences and we further evaluated the antigenicity of selected epitopes for development of diagnostics of visceral leishmaniasis. In order to identify putative diagnostic epitopes, random peptide libraries displayed on the surface of M13 bacteriophages were used as repositories of molecular structures, some of which being supposed to mimic structural regions of Leishmania spp. antigens. The biopanning process led to identification 

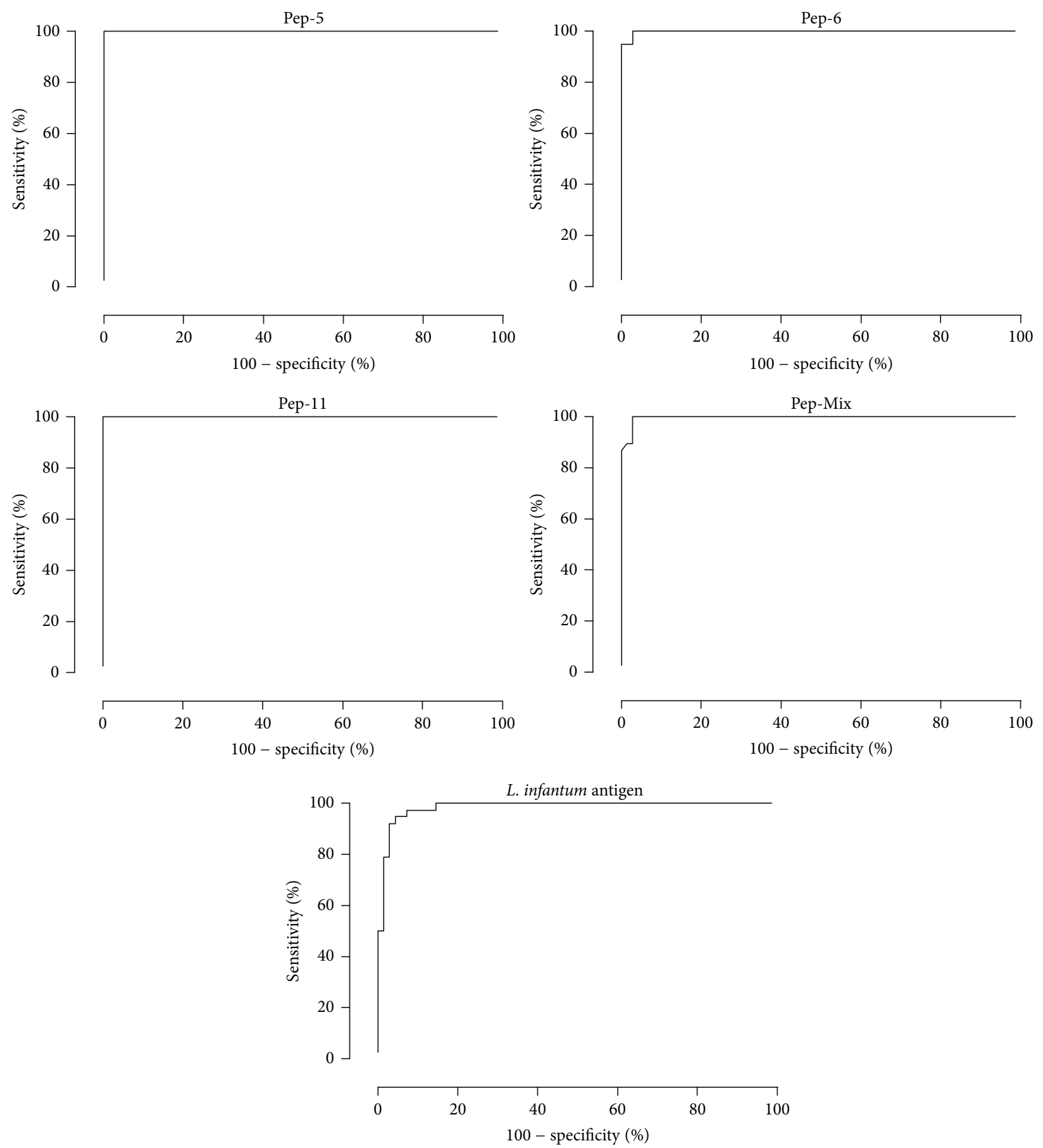

FIGURE 4: ROC curves obtained from all tests. The curves were used to determine ELISA cut-off, sensitivity, specificity, and AUC.

of three peptides sequence (TTDDDKLKKTLTYRS, pep 11; KCPSIPGAVLCV, pep 6; and ICARQDPAGNCS, pep 5) from the $\mathrm{X} 15$ and $X \mathrm{C} X_{8} \mathrm{CX}$ libraries. The comparison of the sequences of the selected peptides with two GenBank peptide sequence databases did not reveal any significant similarity with amino acid sequences of antigens previously characterized from $L$. infantum chagasi, suggesting that selected peptides might correspond either to yet unknown proteins or to conformational epitopes derived from tertiary/quaternary structures of $L$. infantum chagasi proteins. Of note, the two peptides with a disulfide bridge shared a similar motif (PGA for peptide 6 and PAG for peptide 5), which might correspond to a single epitope of an unknown Leishmania protein or a mimotope [29].

The cross-reactivity often described to crude parasite extracts [32, 33, 35-37] was also observed in our study showing that ELISA using L. infantum chagasi (LiPA) and the EIE-LVC ELISA kit recognized antibodies present in a 
TABLE 2: Kappa index $(\kappa)$ between paired results of diagnostic tests using peptides, L. infantum chagasi antigen, and EIE-LVC kit.

\begin{tabular}{|c|c|c|c|c|c|c|}
\hline \multirow{2}{*}{ Diagnostic test } & \multicolumn{3}{|c|}{ EIE-LVC $^{\#}$} & \multicolumn{3}{|c|}{$\mathrm{Ag}^{*}$} \\
\hline & $\mathrm{P}$ & $\mathrm{N}$ & $\mathrm{T}$ & $\mathrm{P}$ & $\mathrm{N}$ & $\mathrm{T}$ \\
\hline \multicolumn{7}{|l|}{ Pep-5* } \\
\hline $\mathrm{P}$ & 36 & 2 & 38 & 36 & 2 & 38 \\
\hline $\mathrm{N}$ & 21 & 48 & 69 & 9 & 60 & 69 \\
\hline $\mathrm{T}$ & 57 & 50 & 107 & 45 & 62 & 107 \\
\hline$\kappa$ index $(95 \% \mathrm{CI})$ & \multicolumn{3}{|c|}{$0.578(0.435-0.721)$, moderate } & \multicolumn{3}{|c|}{$0.784(0.665-0.904)$, good } \\
\hline \multicolumn{7}{|l|}{ Pep-6* } \\
\hline $\mathrm{P}$ & 37 & 3 & 40 & 40 & 0 & 40 \\
\hline $\mathrm{N}$ & 20 & 47 & 67 & 14 & 53 & 67 \\
\hline $\mathrm{T}$ & 57 & 50 & 107 & 54 & 53 & 107 \\
\hline$\kappa$ index $(95 \% \mathrm{CI})$ & \multicolumn{3}{|c|}{$0.557(0.407-0.708)$, moderate } & \multicolumn{3}{|c|}{$0.739(0.616-0.862)$, good } \\
\hline \multicolumn{7}{|l|}{ Pep-11* } \\
\hline $\mathrm{P}$ & 36 & 2 & 38 & 36 & 2 & 38 \\
\hline $\mathrm{N}$ & 21 & 48 & 69 & 9 & 60 & 69 \\
\hline $\mathrm{T}$ & 57 & 50 & 107 & 45 & 62 & 107 \\
\hline$\kappa$ index $(95 \% \mathrm{CI})$ & \multicolumn{3}{|c|}{$0.578(0.435-0.721)$, moderate } & \multicolumn{3}{|c|}{$0.784(0.665-0.904)$, good } \\
\hline \multicolumn{7}{|l|}{ Pep-Mix ${ }^{*}$} \\
\hline $\mathrm{P}$ & 37 & 3 & 40 & 40 & 0 & 40 \\
\hline $\mathrm{N}$ & 20 & 47 & 67 & 14 & 53 & 67 \\
\hline $\mathrm{T}$ & 57 & 50 & 107 & 54 & 53 & 107 \\
\hline$\kappa$ index $(95 \% \mathrm{CI})$ & \multicolumn{3}{|c|}{$0.557(0.407-0.708)$, moderate } & \multicolumn{3}{|c|}{$0.739(0.616-0.862)$, good } \\
\hline \multicolumn{7}{|l|}{$\mathrm{Ag}^{*}$} \\
\hline $\mathrm{P}$ & 41 & 12 & 53 & & & \\
\hline $\mathrm{N}$ & 16 & 38 & 54 & & & \\
\hline $\mathrm{T}$ & 57 & 50 & 107 & & & \\
\hline$\kappa$ index $(95 \% \mathrm{CI})$ & \multicolumn{3}{|c|}{$0.477(0.311-0.643)$, moderate } & & & \\
\hline
\end{tabular}

Samples from healthy dogs and dogs with canine visceral leishmaniasis, T. cruzi, E. canis, or B. canis.

* Cut-off obtained by ROC curve.

\#Cut-off obtained according to the manufacturer.

P: positive; N: negative; T: total; CI: confidence interval.

large number of sera from dog affected by Chagas disease. In contrast, no positive response was observed when the same sera samples were tested using peptide-based (peptides 5 and 11) ELISA. Noteworthy, the ELISA carried out using synthetic peptides 5 and 11 presented a specificity of $100 \%$, while peptide 6 or the pool of the three peptides rendered a specificity of considerable magnitude (97.10\%). Nonetheless, the three peptides were able to detect all Leishmania positive samples (100\% of sensitivity). These results using peptides selected by phage display for LVC immunodiagnosis tests showed better performance than other studies using crude parasite extracts $[20,32,33,38]$, recombinant antigens [3537,39 ], and even synthetic peptides [34]. Of note, in order to provide a better binding of the selected peptides to ELISA plates and enhance their antigenic properties, the mimotopes were covalently polymerized using glutaraldehyde (GLUT) as linker [40].

In summary, our data suggest that the three mimotope peptides identified by phage display would represent highly potential antigens to identify canine visceral leishmaniasis.
Such antigens could be used alone or in combination with promising recombinant antigens in order to maximize the performance of the serological assays. Further studies using large cohorts of negative and positive individuals from endemic areas are still required to determine the use of these antigens (alone or in combination with different recombinant proteins) for control of CVL in endemic areas. Finally, our study suggests that mimotope-based ELISA strategy may be useful for the development of a sensitive and highly specific serodiagnosis for CVL or other parasitic diseases.

\section{Disclosure}

Claudia Martins Carneiro, Carlos Chávez-Olórtegui, and Ricardo Toshio Fujiwara are fellows from CNPq/Brazil.

\section{Conflict of Interests}

The authors declare that there is no conflict of interests regarding the publication of this paper. 


\section{Acknowledgments}

The authors thank Dr. J. Scott for the gift of phage libraries.

\section{References}

[1] M. Gramiccia and L. Gradoni, "The current status of zoonotic leishmaniases and approaches to disease control," International Journal for Parasitology, vol. 35, no. 11-12, pp. 1169-1180, 2005.

[2] J. Moreno and J. Alvar, "Canine leishmaniasis: epidemiological risk and the experimental model," Trends in Parasitology, vol. 18, no. 9, pp. 399-405, 2002.

[3] P. Desjeux, "Focus: leishmaniasis," Nature Reviews Microbiology, vol. 2, no. 9, pp. 692-693, 2004.

[4] F. Mancianti, F. Pedonese, and A. Poli, "Evaluation of dot enzyme-linked immunosorbent assay (dot-ELISA) for the serodiagnosis of canine leishmaniosis as compared with indirect immunofluorescence assay," Veterinary Parasitology, vol. 65, no. 1-2, pp. 1-9, 1996.

[5] M. Cabral, J. E. O’Grady, S. Gomes, J. C. Sousa, H. Thompson, and J. Alexander, "The immunology of canine leishmaniosis: strong evidence for a developing disease spectrum from asymptomatic dogs," Veterinary Parasitology, vol. 76, no. 3, pp. 173-180, 1998.

[6] V. Sideris, G. Papadopoulou, E. Dotsika, and E. Karagouni, "Asymptomatic canine leishmaniasis in Greater Athens area, Greece," European Journal of Epidemiology, vol. 15, no. 3, pp. 271-276, 1999.

[7] A. Moshfe, M. Mohebali, E. Afshoun et al., "Canine visceral leishmaniasis in boyer ahmad district, kohgiluyeh \& boyer ahmad province, Southwest of Iran," Iranian Journal of Parasitology, vol. 7, no. 4, pp. 75-81, 2012.

[8] R. Fisa, C. Riera, M. Gállego, J. Manubens, and M. Portús, "Nested PCR for diagnosis of canine leishmaniosis in peripheral blood, lymph node and bone marrow aspirates," Veterinary Parasitology, vol. 99, no. 2, pp. 105-111, 2001.

[9] R. B. Tesh, "Control of zoonotic visceral leishmaniasis: is it time to change strategies?" American Journal of Tropical Medicine and Hygiene, vol. 52, no. 3, pp. 287-292, 1995.

[10] Ministério da Saúde, Manual de Vigilância e Controle da Leishmaniose Visceral, Ministério da Saúde, São Paulo, Brazil, 2006.

[11] W. A. Alves and P. D. Bevilacqua, "Quality of diagnosis of canine visceral leishmaniasis in epidemiological surveys: an epidemic in Belo Horizonte, Minas Gerais, Brazil, 1993-1997," Cadernos de Saúde Pública, vol. 20, no. 1, pp. 259-265, 2004.

[12] E. S. Silva, C. M. F. Gontijo, and M. N. Melo, "Contribution of molecular techniques to the epidemiology of neotropical Leishmania species," Trends in Parasitology, vol. 21, no. 12, pp. 550-552, 2005.

[13] G. Matlashewski, B. Arana, A. Kroeger et al., "Visceral leishmaniasis: elimination with existing interventions," The Lancet Infectious Diseases, vol. 11, no. 4, pp. 322-325, 2011.

[14] O. Noya, M. E. Patarroyo, F. Guzmán, and B. A. de Noya, "Immunodiagnosis of parasitic diseases with synthetic peptides," Current Protein and Peptide Science, vol. 4, no. 4, pp. 299308, 2003.

[15] G. P. Smith, "Filamentous fusion phage: novel expression vectors that display cloned antigens on the virion surface," Science, vol. 228, no. 4705, pp. 1315-1317, 1985.
[16] J. K. Scott and G. P. Smith, "Searching for peptide ligands with an epitope library," Science, vol. 249, no. 4967, pp. 386-390, 1990.

[17] K. Manoutcharian, A. Díaz-Orea, G. Gevorkian et al., "Recombinant bacteriophage-based multiepitope vaccine against Taenia solium pig cysticercosis," Veterinary Immunology and Immunopathology, vol. 99, no. 1-2, pp. 11-24, 2004.

[18] R. Lanzillotti and T. L. Coetzer, "Phage display: a useful tool for malaria research?” Trends in Parasitology, vol. 24, no. 1, pp. 1823, 2008.

[19] R. C. R. Hell, P. Amim, H. M. de Andrade et al., "Immunodiagnosis of human neurocysticercosis using a synthetic peptide selected by phage-display," Clinical Immunology, vol. 131, no. 1, pp. 129-138, 2009.

[20] M. Z. Troncarelli, J. B. Camargo, J. G. Machado, S. B. Lucheis, and H. Langoni, "Leishmania spp. and/or Trypanosoma cruzi diagnosis in dogs from endemic and nonendemic areas for canine visceral leishmaniasis," Veterinary Parasitology, vol. 164, no. 2-4, pp. 118-123, 2009.

[21] M. M. Bradford, "A rapid and sensitive method for the quantitation of microgram quantities of protein utilizing the principle of protein dye binding," Analytical Biochemistry, vol. 72, no. 1-2, pp. 248-254, 1976.

[22] P. L. Ey, S. J. Prowse, and C. R. Jenkin, "Isolation of pure $\operatorname{IgG}_{1}$, $\mathrm{IgG}_{2 a}$ and $\mathrm{IgG}_{2 b}$ immunoglobulins from mouse serum using protein A-sepharose," Immunochemistry, vol. 15, no. 7, pp. 429436, 1978.

[23] L. L. C. Bonnycastle, J. S. Mehroke, M. Rashed, X. Gong, and J. K. Scott, "Probing the basis of antibody reactivity with a panel of constrained peptide libraries displayed by filamentous phage," Journal of Molecular Biology, vol. 258, no. 5, pp. 747-762, 1996.

[24] G. Ferrières, S. Villard, M. Pugnière et al., "Affinity for the cognate monoclonal antibody of synthetic peptides derived from selection by phage display. Role of sequences flanking the binding motif," European Journal of Biochemistry, vol. 267, no. 6, pp. 1819-1829, 2000.

[25] F. Sanger, S. Nicklen, and A. R. Coulson, "DNA sequencing with chain-terminating inhibitors," Proceedings of the National Academy of Sciences of the United States of America, vol. 74, no. 12, pp. 5463-5467, 1977.

[26] H. Gausepohl, C. Boulin, M. Kraft, and R. W. Frank, "Automated multiple peptide synthesis," Peptide Research, vol. 5, no. 6, pp. 315-320, 1992.

[27] R. A. M. de Avila, S. Stransky, M. Velloso et al., "Mimotopes of mutalysin-II from Lachesis muta snake venom induce hemorrhage inhibitory antibodies upon vaccination of rabbits," Peptides, vol. 32, no. 8, pp. 1640-1646, 2011.

[28] E. Harlow and D. Lane, Antibodies: A Laboratory Manual, Cold Spring Harbor Laboratory, Cold Spring Harbor, NY, USA, 1988.

[29] H. M. Geysen, S. J. Rodda, and T. J. Mason, "A priori delineation of a peptide which mimics a discontinuous antigenic determinant," Molecular Immunology, vol. 23, no. 7, pp. 709-715, 1986.

[30] J. L. Fleiss, R. L. Spitzer, J. Endicott, and J. Cohen, "Quantification of agreement in multiple psychiatric diagnosis," Archives of General Psychiatry, vol. 26, no. 2, pp. 168-171, 1972.

[31] S. D. Walter, "Properties of the summary receiver operating characteristic (SROC) curve for diagnostic test data," Statistics in Medicine, vol. 21, no. 9, pp. 1237-1256, 2002.

[32] M. F. Znette, V. M. Lima, M. D. Laurenti et al., "Serological cross-reactivity of Trypanosoma cruzi, Ehrlichia canis, Toxoplasma gondii, Neospora caninum and Babesia canis to Leishmania infantum chagasi tests in dogs," Revista da Sociedade Brasileira de Medicina Tropical, vol. 47, no. 1, pp. 105-107, 2014. 
[33] S. Sundar and M. Rai, "Laboratory diagnosis of visceral leishmaniasis," Clinical and Diagnostic Laboratory Immunology, vol. 9, no. 5, pp. 951-958, 2002.

[34] M. M. Costa, M. Penido, M. S. Santos et al., "Improved canine and human visceral leishmaniasis immunodiagnosis using combinations of synthetic peptides in enzyme-linked immunosorbent assay," PLoS Neglected Tropical Diseases, vol. 6, no. 5, Article ID e1622, 2012.

[35] D. Menezes-Souza, T. A. de Oliveira Mendes, A. C. de Araújo Leão, M. de Souza Gomes, R. T. Fujiwara, and D. C. Bartholomeu, "Linear B-cell epitope mapping of MAPK3 and MAPK4 from Leishmania braziliensis: implications for the serodiagnosis of human and canine leishmaniasis," Applied Microbiology and Biotechnology, 2014.

[36] D. Menezes-Souza, T. A. Mendes, S. Gomes Mde et al., "Epitope mapping of the HSP83.1 protein of Leishmania braziliensis discloses novel targets for immunodiagnosis of tegumentary and visceral clinical forms of leishmaniasis," Clinical and Vaccine Immunology, vol. 21, no. 7, pp. 949-959, 2014.

[37] D. Menezes-Souza, T. A. Mendes, R. A. Nagem et al., "Mapping B-cell epitopes for the peroxidoxin of Leishmania (Viannia) braziliensis and its potential for the clinical diagnosis of tegumentary and visceral leishmaniasis," PLoS ONE, vol. 9, no. 6, Article ID e99216, 2014.

[38] D. A. D. Silva, M. D. F. Madeira, T. R. Abrantes, C. J. D. L. B. Filho, and F. B. Figueiredo, "Assessment of serological tests for the diagnosis of canine visceral leishmaniasis," Veterinary Journal, vol. 195, no. 2, pp. 252-253, 2013.

[39] Z. Maia, M. Lírio, S. Mistro, C. M. C. Mendes, S. R. Mehta, and R. Badaro, "Comparative study of rK39 Leishmania antigen for serodiagnosis of visceral leishmaniasis: systematic review with meta-analysis," PLoS Neglected Tropical Diseases, vol. 6, no. 1, Article ID e1484, 2012.

[40] J. Ramos-Jesus, K. A. Carvalho, R. A. S. Fonseca et al., "A piezoelectric immunosensor for Leishmania chagasi antibodies in canine serum," Analytical and Bioanalytical Chemistry, vol. 401, no. 3, pp. 917-925, 2011. 

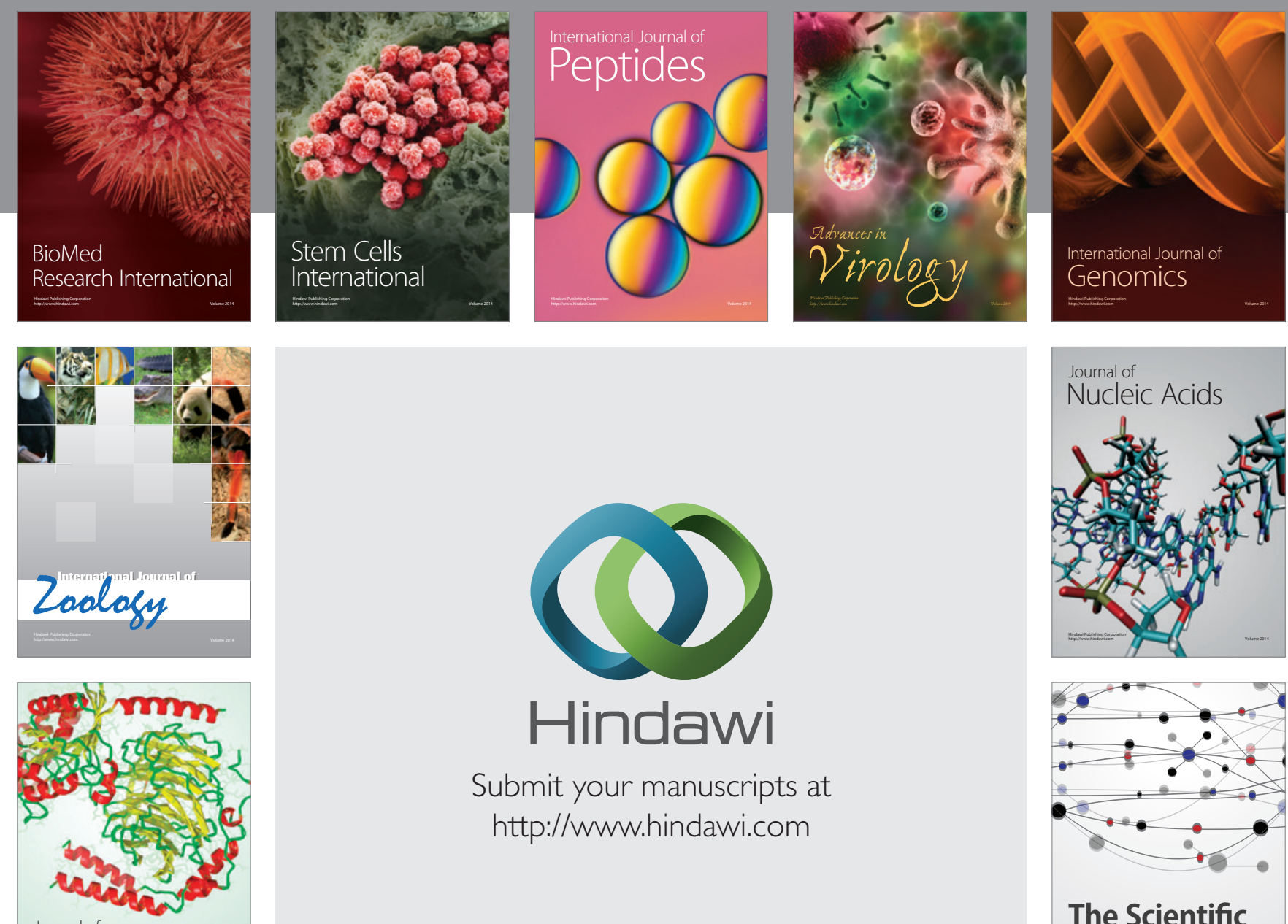

Submit your manuscripts at

http://www.hindawi.com

Journal of
Signal Transduction
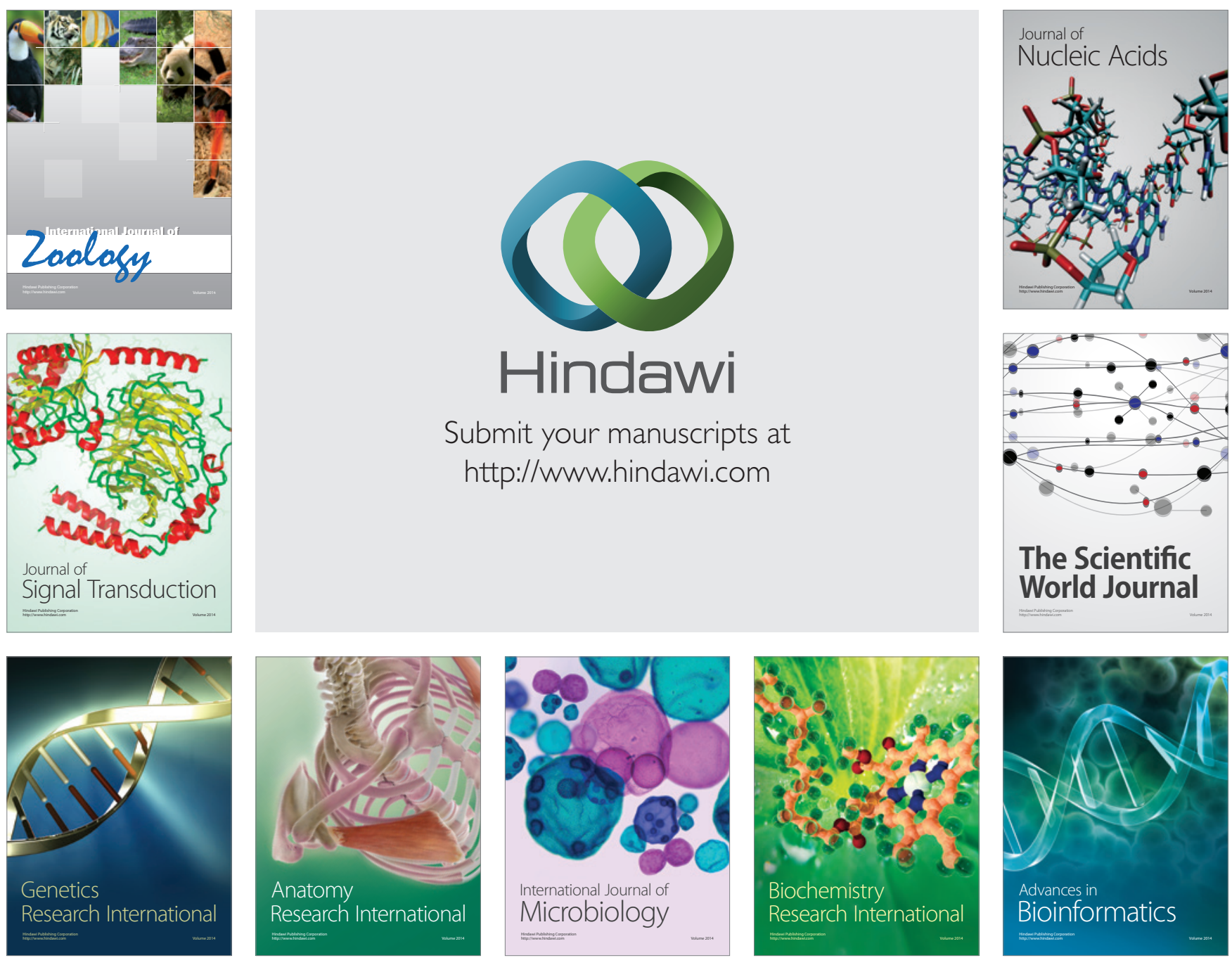

The Scientific World Journal
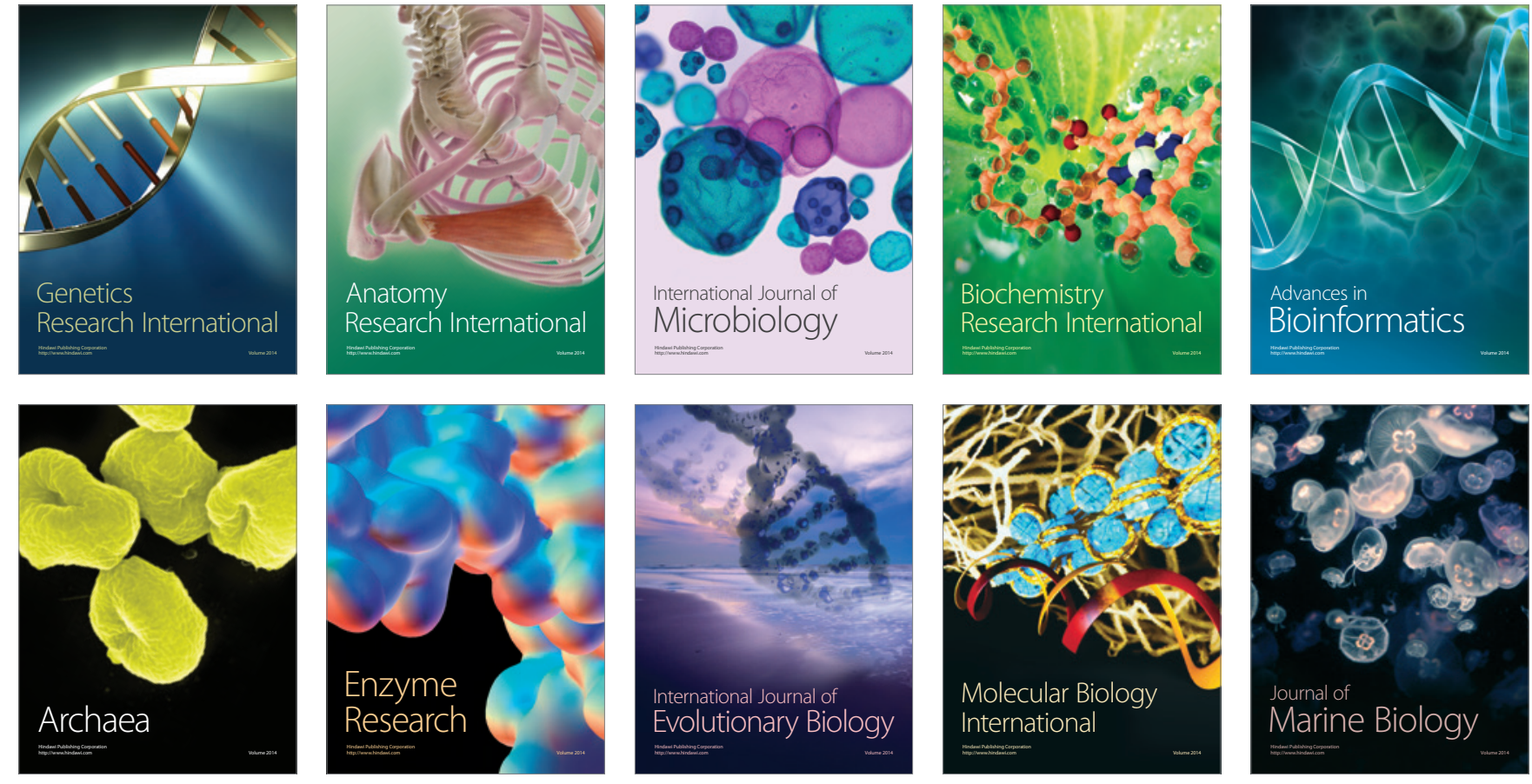